\title{
A research on sources of university faculty occupational stress: a Chinese case study
}

This article was published in the following Dove Press journal: Psychology Research and Behavior Management

\section{Qian Meng \\ Guan Wang}

Department of Higher Education, College of Education, Bohai University, Jinzhou 121013 , China
Correspondence: Qian Meng

Department of Higher Education, College of Education, Bohai University, 19 Keji

Road, Jinzhou 121013 , China

Tel/fax+864163400230

Email mengqian_china@hotmail.com
Background: The aim of this study was to investigate the stress level of university faculty members, the important determinants of faculty members' stress, and the implications for both faculty members and administrators.

Subjects and methods: Participants were asked to complete a questionnaire consisting of 24 questions. Reponses from 240 participants at a Chinese university were analyzed using SPSS software. The descriptive statistics showed the participants' statistical characteristics. Cronbach's $\alpha$ and varimax rotation were used to assess the reliability and validity of the scale. The main statistical methods used were ANOVA and multifactor line regression.

Results: University faculty members' occupational stress is widespread across occupational hierarchies. University faculty members are faced with different levels of teaching and scientific research and personal development pressures. Professional ranking, age, and length of teaching make a difference in the level of faculty members' occupational stress. The results can help us confirm that scientific research, professional development, and administrative affairs are significant influencing factors of faculty members' occupational stress.

Conclusion: University faculty members' occupational stress is the outcome of structural constraints of university and personal characteristics. On the one hand, the faculty members should recognize the positive impact of occupational stress while striving to eliminate stressors. On the other hand, this empirical study uncovered that the evaluation mechanism based on quantitative performance indicators has greatly increased the occupational pressure on university faculty members. Keywords: university faculty, occupational stress, personal characteristics, performance evaluation

\section{Introduction}

In the field of industrial-organizational psychology, work stress is considered to be a reaction to stimuli in a job that leads to negative consequences for the people exposed to these stimuli. ${ }^{1}$ Since 1999 , the rapid expansion of higher education in China has exerted a great impact on the professional workload of university faculty members. According to a survey, due to the enrollment expansion in colleges and universities, the average class size is 83 students. ${ }^{2}$ Teaching is no longer merely hard work; it has become a highly stressful profession. ${ }^{3}$ Currently, the university faculty members face challenges relating to the diverse needs of students and performance requirements. This often leads to overwhelming pressure, which consequently leads to stress and conflict.

The university faculty members have numerous responsibilities, such as conducting scientific research, teaching, and carrying out various types of social work. These responsibilities are placing an increasingly heavy burden on the faculty members. The 
functions of university faculty members include teaching and mentoring students and preparing papers and presentations for both class lectures and research conferences. Faculty members must also perform nonacademic functions that include family life, social life, and community commitments. Given their numerous roles and responsibilities, and the intense demands and high expectations placed on them, many university faculty members experience significant levels of stress, and this leads to increased turnover intent, decreased job performance, decreased job satisfaction, increased anxiety, and increased depression. ${ }^{4-6}$

Many factors affect the stress levels of university faculty members. Work overload can lead to high pressure which causes physical and emotional exhaustion. ${ }^{7}$ Some respondents reported increased student numbers as a cause of stress, because they had to meet the requirements of different students. ${ }^{8,9}$ Besides, lack of university support, such as resources, funding, and recognition, is also the source of occupational stress. ${ }^{10}$ Employees who have low job satisfaction suffered more stress and have a greater propensity to leave universities. ${ }^{5,11}$ Too many administrative affairs have occupied too much teaching and research time and made faculty members feel stressed..$^{12}$ There is a relationship between occupational stress and work-life imbalance. ${ }^{13}$ In addition, ineffective coping style can also lead to occupational stress. ${ }^{14}$

Other demographic factors, including gender and age, can affect the stress level of faculty members. Women scored significantly higher than men. ${ }^{15,16}$ Occupational stress differed between different ages. ${ }^{17,18}$ Finding reveals that professional ranking or career development was the greatest source of occupational stress. ${ }^{19,20}$ In addition, years of teaching experience also contribute to the stress levels of university faculty members. ${ }^{8,18}$

There are two drastically different views on the work overload of university faculty members. One view holds that the high-intensity work burden of university faculty members is self-imposed and based on the love of, and dedication to, the job. The other view considers this burden as the outcome of structural constraints under the expectations of universities. Nonacademic work, such as meeting the high threshold for tenure, endless administrative affairs, preparing for and attending conferences, external reviews, and considerable e-mailing, increases this burden. ${ }^{2}$

The concept of new public management has changed the relationship between universities, the government, and the market. Hence, the operation of university organizations is more consistent with market rules, and the importance of efficiency is emphasized. The so-called ivory tower has come under the control of academic capitalism. Furthermore, the implementation of the new public management mode and quantitative evaluation method has increased the labor load, thereby heightening the psychological pressure on the university faculty members. Owing to the popularization and seriousness of this topic, the psychological stress that university faculty members endure is attracting more scholarly attention.

As teaching is a highly stressful profession, the aim of this study was to investigate the stress level of university faculty members, the important determinants of faculty members' stress, and the implications for both faculty members and administrators. As such, the following research questions were formulated:

Q1: What is the occupational stress level of university faculty members?

Q2: What are the factors influencing the occupational stress of university faculty members?

Q3: What are the implications for both faculty members and administrators?

\section{Subjects and methods Sample}

The sample comprised 240 (109 males and 131 females) faculty members from a large university in Jinzhou, Liaoning Province, China. A random sample was chosen for the study, and participation was completely voluntary. The 240 valid returned questionnaires constituted $96 \%$ of the questionnaires were distributed. The age of the faculty members ranged from 30 to 58 years. The ascending faculty members' ranking is assistant professor, associate professor, and professor. Retired or part-time faculty members were excluded from the sample. In accordance with the Declaration of Helsinki, written informed consent must have been provided by the participants prior to fill the questionnaire. The ethics committee of Bohai University approved this study. The descriptive statistics of participants are summarized in Table 1.

\section{Procedure}

This study was conducted between March 2018 and August 2018. Participants were recruited at random from three major subjects: liberal arts, science, and engineering. We stated the purpose of the questionnaire and assured them that their answers would remain confidential. Returning of the questionnaire implied consent to participate in the study. Participants were asked to answer a paper question- 
naire and were informed of their right to withdraw from the study if they felt uncomfortable. Participants were told that they had right to refuse to answer any particular question and no participants will be named in the publications and every effort will be made to disguise their identity. In the last part of the questionnaire, participants could choose to leave their e-mail address if they were interested in receiving a summary of the results.

\section{Structure of the scale}

According to the results of the reviewed studies, we identified the main stressors: teaching, academic research, administrative affairs, personal relationships, professional development, promotion, and health issues. Drawing on the results of an open survey and interviews, we designed a questionnaire consisting of 24 items with answers ranked on a 4-point scale: $1=$ no stress, $2=$ mild stress, $3=$ moderate stress, $4=$ severe stress. All statistical analyses were performed using SPSS statistic software.

The results of the Kaiser-Meyer-Olkin (KMO) index and Bartlett's spherical test are summarized in Table 2. As summarized in the table, the KMO value was 0.89 , which met the requirement for factor analysis. Moreover, the result

Table I Sample distribution: participant characteristics

\begin{tabular}{|l|l|l|}
\hline & Frequency & Percent \\
\hline Gender & 109 & \\
Male & 131 & 45.4 \\
Female & & 54.6 \\
Age (years) & 105 & \\
$30-40$ & 108 & 43.8 \\
$40-50$ & 27 & 45.0 \\
$50+$ & & 11.3 \\
Degree & 112 & \\
Doctor & 101 & 46.7 \\
Master & 27 & 42.1 \\
Bachelor & & 11.3 \\
Major & 81 & \\
Liberal arts & 99 & 33.8 \\
Science & 60 & 41.3 \\
Engineering & & 25.0 \\
Professional ranking & 43 & \\
Professor & 81 & 17.9 \\
Associate professor & 116 & 33.8 \\
Assistant professor & & 48.3 \\
Length of teaching (years) & 39 & 16.3 \\
0-3 & 92 & 38.3 \\
3-9 & 59 & 24.6 \\
9-15 & 50 & 20.8 \\
15+ & 240 & 100 \\
Total & & \\
\hline
\end{tabular}

of the Bartlett's spherical test was $P<0.001$, showing that the data were suitable for factor analysis (Table 2).

Next, we used the varimax rotation method to analyze the structure of the scale. The determination of the subscale was based on the principle that the eigenvalue is $>1$. We extracted five factors from the 24 questions, which explained $61.3 \%$ of the total variation. The results of the factor analysis are summarized in Table 3.

The five factors are as follows:

Factor I: scientific research

Factor II: professional development

Factor III: teaching support

Factor IV: administrative affairs

Factor V: health issues

The score range for the university faculty stress scale was 24-96. The score range for the academic research subscale was 9-36. The score range for professional development subscale was 6-24. The score range for the teaching support subscale was 5-20. The score range for the administrative affairs subscale was 3-12. Lastly, the score range for the health issues subscale was $1-4$. Therefore, a score below 24 meant no stress, a score ranging from 24 to 48 meant mild stress, a score ranging from 48 to 72 meant moderate stress, and a score above 72 meant severe stress. The higher the score on the above scale, the greater the stress.

\section{Reliability of the scale}

Using structural analysis, we examined the internal consistency reliability of the scale and subscales. The results showed that the internal consistency of the scale and subscales was good. The results of the reliability test are summarized in Table 4. Cronbach's $\alpha$ was 0.92 for the total scale and $0.52-0.88$ for subscales. This shows that the scale is a valid and reliable tool for measuring university faculty members' occupational stress and can be used to determine the sources of faculty members' occupational stress.

\section{Statistical analyses}

All statistical data were analyzed with SPSS software. The descriptive statistics showed the statistical characteristics of

Table $2 \mathrm{KMO}$ and Bartlett's test

\begin{tabular}{|l|l|}
\hline Measure/test & Result \\
\hline KMO measure of sampling adequacy & 0.916 \\
Bartlett's test of sphericity & \\
Approx. chi-square & $2,286.875$ \\
df & 276 \\
Sig. & 0.000 \\
\hline
\end{tabular}

Note: KMO $>0.70$ is suitable for factor analysis. Abbreviation: KMO, Kaiser-Meyer-Olkin. 
Table 3 Factor loadings for exploratory factor analysis with varimax rotation of university faculty members' occupational stress

\begin{tabular}{|c|c|c|c|c|c|}
\hline \multirow[t]{2}{*}{ Components } & \multicolumn{5}{|c|}{ Factor loading } \\
\hline & Factor I & Factor II & Factor III & Factor IV & Factor $\mathrm{V}$ \\
\hline \multicolumn{6}{|l|}{ Factor I $(35.4 \mid \%$, eigenvalue $=8.5)$} \\
\hline Q12 & 0.75 & & & & \\
\hline Q14 & 0.67 & & & & \\
\hline Q10 & 0.67 & & & & \\
\hline QII & 0.66 & & & & \\
\hline Q4 & 0.62 & & & & \\
\hline Q16 & 0.61 & & & & \\
\hline QI & 0.60 & & & & \\
\hline Q13 & 0.58 & & & & \\
\hline Q2 & 0.50 & & & & \\
\hline \multicolumn{6}{|l|}{ Factor II $(7.41 \%$, eigenvalue $=1.78)$} \\
\hline Q22 & & 0.66 & & & \\
\hline Q20 & & 0.64 & & & \\
\hline Q21 & & 0.63 & & & \\
\hline Q24 & & 0.57 & & & \\
\hline Q18 & & 0.57 & & & \\
\hline Q19 & & 0.48 & & & \\
\hline \multicolumn{6}{|l|}{ Factor III $(5.5 \mathrm{I} \%$, eigenvalue $=1.32)$} \\
\hline Q7 & & & 0.73 & & \\
\hline Q9 & & & 0.68 & & \\
\hline Q17 & & & 0.55 & & \\
\hline Q15 & & & 0.53 & & \\
\hline \multicolumn{6}{|l|}{ Factor IV $(4.76 \%$, eigenvalue $=1.14)$} \\
\hline Q6 & & & & 0.64 & \\
\hline Q3 & & & & 0.64 & \\
\hline Q5 & & & & 0.58 & \\
\hline \multicolumn{6}{|l|}{ Factor $\vee(4.42 \%$, eigenvalue $=1.06)$} \\
\hline Q8 & & & & & 0.57 \\
\hline Q23 & & & & & 0.63 \\
\hline
\end{tabular}

Notes: Factor I: scientific research. Factor II: professional development. Factor III: teaching support. Factor IV: administrative affairs. Factor V: health issues.

Abbreviation: Q, question.

Table 4 Internal consistency reliability of university faculty stress scale

\begin{tabular}{|l|l|}
\hline Scales & Cronbach's $\boldsymbol{\alpha}$ \\
\hline University faculty stress scale & 0.92 \\
Scientific research subscale & 0.88 \\
Professional development subscale & 0.80 \\
Teaching support subscale & 0.68 \\
Administrative affairs subscale & 0.69 \\
Health issues subscale & 0.52 \\
\hline
\end{tabular}

Note: $\alpha>0.50$ shows that scales have good reliability.

participants. Cronbach's $\alpha$ indicated the coherence and internal consistency of the questionnaire, and varimax rotation was used for constructing the questionnaire and extracting the factors. We used ANOVA to test whether there were significant differences among participants owing to age, professional ranking, and length of teaching. The main statistical tool for this questionnaire was multifactor line regression to determine the important factor in increasing university faculty members' occupational stress.

\section{Results}

\section{University faculty members' occupational stress level}

As we can conclude from Table 5 that the average score of all participants is 58.58. The assistant professors' average score was 61.42 , which was higher than the scores of associate professors (58.94) and professors (50.20). All scores fell within the range of 48-72, indicating that university faculty members' occupational stress is widespread across occupational hierarchies, and most of the faculty members are experiencing moderate stress.

\section{The correlation between individual characteristics and stress}

Next, we explored the possibility of whether individual characteristics affect the occupational stress of the university faculty members. The results did not show a significant correlation between gender $(\mathrm{t}=0.464, P=0.643>0.05)$, degree $(F=1.413$, $P=0.246>0.05)$, major $(F=1.458, P=0.235>0.05)$, and occu- 
Table 5 Mean score of university faculty members' stress for different professional rankings

\begin{tabular}{|l|l|l|l|}
\hline Professional ranking & Mean & N & SD \\
\hline Professor & 50.21 & 43 & 9.62 \\
Associate professor & 58.94 & 81 & 14.07 \\
Assistant professor & 61.42 & 116 & 13.71 \\
Total & 58.58 & 240 & 13.77 \\
\hline
\end{tabular}

pational stress. However, age $(F=3.790, P=0.024<0.05)$, professional ranking $(F=11.35, P=0.000<0.01)$, and length of teaching $(F=3.53, P=0.016<0.05)$ were highly related to occupational stress.

The abovementioned test indicated significant effects of age, length of teaching, and professional ranking on faculty members' occupational stress. The $P$-value of the three sets of data was $<0.05$, allowing us to reject the null hypothesis. Moreover, we observed significant effects of age, length of teaching, and professional ranking on faculty members' occupational stress. Therefore, with age, faculty members' occupational stress gradually decreases. The mean value of age 30-40 years was 61.28 ; however, the mean values of ages $40-50$ and $50+$ years were 57.59 and 56.19 , respectively. In addition, faculty members with different professional rankings experienced different levels of stress. The mean value for assistant professor $(M=61.42)$ was higher than that for associate professor $(M=58.94)$ and professor $(M=50.21)$. Finally, years of teaching were an influencing factor of faculty members' occupational stress (Table 6).

\section{The occupational stressors of university faculty members}

Regarding the sources of stress, the results show that the main stressor for assistant and associate professors was scientific research, with cumulative contributions of $61.57 \%$ and $67.52 \%$, respectively. While the main stressors for professors were scientific research and professional development, the cumulative contributions were $47.2 \%$ and $21.15 \%$, respectively (Figure 1).

Table 7 summarizes the multiline regression of influencing factors of university faculty members' stress. Questions 1 , $4,6,11,19$, and 20 were highly related to faculty members' occupational stress. Combined with the results in Table 3, we can see that questions 1 and 20 related to scientific research, questions 4 and 11 related to professional development, and questions 6 and 19 related to administrative affairs. The results can help us confirm that scientific research, professional development, and administrative affairs are the sig- nificant influencing factors of faculty members' occupational stress and find ways to deal with them.

\section{Discussion}

This study used a university faculty occupational stress scale to identify the general value of occupational stress and stressors of university faculty members, who differed with respect to gender, degree, age, professional ranking, major, and length of teaching. What level of occupational stress do university faculty members face? What is at the root of this stress? How should university faculty members cope with these pressures? Using data from 240 teachers' responses to a questionnaire, an empirical study was conducted to answer the abovementioned questions. The conclusions of this study can be summed up as follows.

First, with the expansion of university enrollment, the rapid progress of social science and technology, and the penetration of new public management ideas, students' diverse needs and academic performance are influencing universities' management mechanism more than ever before. As the results of the data analysis indicate, university faculty members are in a highly stressful profession. The mean value of all participants was 58.58, indicating that the university faculty members were more or less under different levels of pressure. It proves the existence of university faculty members' occupational stress (Q1). Universities have been adopting the performance evaluation mechanism to enhance the output of university faculty members. However, this mechanism only leads to heightened faculty members' stress, and such stress has not transformed into effective pressure that promotes an increase in the faculty members' academic output.

There could be several explanations for this finding. One explanation could be role overload. For example, many participants reported that they are entangled in too many nonacademic affairs. This finding supports Gupta et al's ${ }^{7}$ assertion that a heavy workload is often considered to be a major source of occupational stress. Faculty members must juggle different roles and social responsibilities, but they do not receive remuneration or the social support they deserve. Moreover, role overload increases pressure, which is in line with the findings of Khan et al, ${ }^{4}$ Reevy and Deason, ${ }^{5}$ and Veena et al. ${ }^{6}$

Second, five factors contribute to faculty members' occupational stress, namely scientific research, professional development, teaching support, administrative affairs, and health issues. According to the results of regression analysis, scientific research, professional development, and administrative affairs have significant effect on university faculty 
Table 6 Significance test of university faculty members' occupational stress

\begin{tabular}{|c|c|c|c|c|}
\hline \multicolumn{5}{|l|}{ Age $(F=3.790, P=0.024<0.05)$} \\
\hline (I) Age (years) & (J) Age (years) & $\begin{array}{l}\text { Mean difference } \\
(I-J)\end{array}$ & Sig. & Mean \\
\hline \multirow[t]{2}{*}{$30-40$} & $40-50$ & $5.08^{*}$ & 0.007 & 61.28 \\
\hline & $50+$ & 3.68 & 0.211 & \\
\hline \multirow[t]{2}{*}{$40-50$} & $30-40$ & $-5.08^{*}$ & 0.007 & 57.59 \\
\hline & $50+$ & -1.40 & 0.634 & \\
\hline \multirow[t]{2}{*}{$50+$} & $30-40$ & -3.68 & 0.211 & 56.19 \\
\hline & $40-50$ & 1.40 & 0.634 & \\
\hline \multicolumn{5}{|c|}{ Professional ranking $(F=11.349, P=0.000<0.01)$} \\
\hline (I) Professional ranking & (J) Professional ranking & $\begin{array}{l}\text { Mean difference } \\
(I-J)\end{array}$ & Sig. & Mean \\
\hline \multirow[t]{2}{*}{ Professor } & Assistant professor & $-8.73^{*}$ & 0.001 & 50.21 \\
\hline & Associate professor & $-11.21 *$ & 0.000 & \\
\hline \multirow[t]{2}{*}{ Associate professor } & Professor & $8.73 *$ & 0.001 & 58.94 \\
\hline & Assistant professor & -2.48 & 0.195 & \\
\hline \multirow[t]{2}{*}{ Assistant professor } & Professor & $11.21 *$ & 0.000 & 61.42 \\
\hline & Associate professor & 2.48 & 0.195 & \\
\hline \multicolumn{5}{|c|}{ Length of teaching $(F=3.526, P=0.016<0.05)$} \\
\hline (I) Length of teaching (years) & (J) Length of teaching (years) & $\begin{array}{l}\text { Mean difference } \\
(I-J)\end{array}$ & Sig. & Mean \\
\hline \multirow[t]{3}{*}{$0-3$} & $3-9$ & 0.32 & 0.900 & 56.56 \\
\hline & $9-15$ & -2.74 & 0.328 & \\
\hline & $15+$ & $-7.01 *$ & 0.016 & \\
\hline \multirow[t]{3}{*}{$3-9$} & $0-3$ & -0.32 & 0.900 & 56.23 \\
\hline & $9-15$ & -3.07 & 0.176 & \\
\hline & $15+$ & $-7.34^{*}$ & 0.002 & \\
\hline \multirow[t]{3}{*}{$9-15$} & $0-3$ & 2.74 & 0.328 & 59.31 \\
\hline & $3-9$ & 3.07 & 0.176 & \\
\hline & $15+$ & -4.27 & 0.102 & \\
\hline \multirow{3}{*}{$15+$} & $0-3$ & $7.01 *$ & 0.016 & 63.58 \\
\hline & $3-9$ & $7.34^{*}$ & 0.002 & \\
\hline & $9-15$ & 4.27 & 0.102 & \\
\hline
\end{tabular}

Notes: $* P<0.05 . \mathrm{I}=$ group $\mathrm{I} ; \mathrm{J}=$ group $\mathrm{J}$.

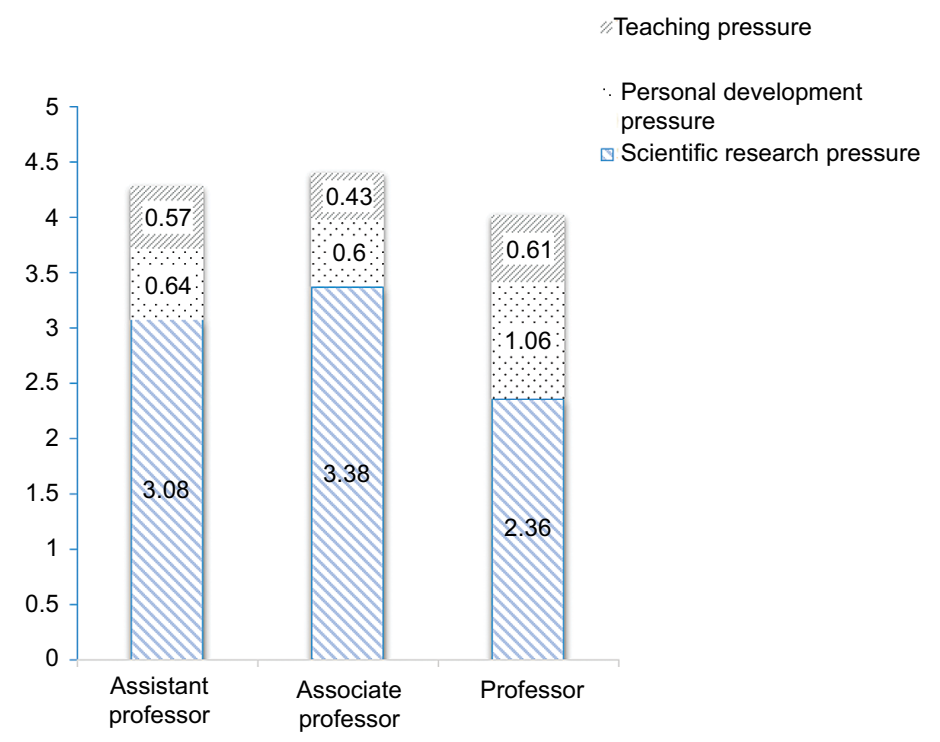

Figure I Structure of occupational stress sources for different professional rankings. 
Table 7 Multifactor line regression of university faculty members' occupational stress

\begin{tabular}{|c|c|c|c|c|c|}
\hline & \multicolumn{2}{|c|}{ Unstandardized coefficients } & \multirow{2}{*}{$\begin{array}{l}\text { Standardized } \\
\text { coefficients } \\
\text { Beta }\end{array}$} & \multirow[t]{2}{*}{$\mathbf{T}$} & \multirow[t]{2}{*}{ Sig. } \\
\hline & B & $\begin{array}{l}\text { Standard } \\
\text { error }\end{array}$ & & & \\
\hline (Constant) & 48.584 & 0.633 & & 76.709 & 0.000 \\
\hline Scientific research pressure & 3.346 & 1.495 & 0.111 & $2.238^{*}$ & 0.026 \\
\hline Professional ranking evaluation & 2.998 & 1.269 & 0.107 & $2.362^{*}$ & 0.019 \\
\hline Administrative interference & 3.683 & 1.540 & 0.106 & $2.392 *$ & 0.018 \\
\hline Strict performance evaluation & 4.406 & 1.599 & 0.135 & $2.755^{* *}$ & 0.006 \\
\hline Too much nonacademic work & 3.936 & 1.582 & 0.118 & $2.487 *$ & 0.014 \\
\hline $\begin{array}{l}\text { Bad atmosphere of scientific } \\
\text { research team }\end{array}$ & 3.911 & 1.727 & 0.094 & $2.265^{*}$ & 0.025 \\
\hline
\end{tabular}

Note: $* P<0.05,{ }^{* * P}<0.01$.

members' occupational stress. This answers Q2 by showing that there are many synthetic sources of faculty members' occupational stress. University faculty members are trapped by demands for a high level of teaching, scientific research output, and professional development.

The change to the university management and evaluation system is also an external driving force behind the increase in occupational stress for university faculty members. The pursuit of high teaching quality and the quantitative evaluation mechanism of academic output have dramatically changed the academic environment for faculty members, which has led to high occupational stress. No previous studies in the literature review mentioned the impact that the university management and evaluation system have on faculty members' occupational stress. This may be related to the mode of professional autonomy and self-regulation that Western universities adhere to, rather than public accountability or policy intervention. In the context of China's development of world-class universities, the institutions focus on improving teaching quality and increasing academic output, which inevitably increases professional pressure on the faculty members.

Third, the personal characteristics of university faculty members are important factors that affect faculty members' occupational stress. In particular, faculty members under 40 years old are suffering from a high level of occupational stress due to the heavy economic pressure from family and the challenge of teaching and conducting scientific research. In addition, assistant professors experience greater occupational stress than associate professors and professors. In universities, professional ranking determines salary, academic status, and research resources. Therefore, seeking promotion has also become a source of faculty members' occupational stress. Further, since the proportion of junior faculty members employed as assistant professors is the largest, this indirectly explains why faculty members under 40 years old have the highest occupational stress.

This result for age supports the findings of Akbar et $\mathrm{a}^{17}$ and Merchant et al, ${ }^{18}$ as younger faculty members feel more stress in their academic work and with balancing work and family, especially when the competition for academic promotions is extremely intense. In contrast to Merchant et al's ${ }^{17}$ findings, the results of the present study suggest that the longer the years of teaching, the greater the occupational stress. Several respondents with more than 15 years of teaching experience reported that they are eager to enhance the use of information technology. In the technological era, students prefer online learning to traditional classroom teaching. Moreover, unlike Donovan's ${ }^{15}$ results, surprisingly, there were no obvious gender differences in the university faculty members' occupational stress. This may be because female and male teachers must meet the same evaluation criteria.

Therefore, the university faculty members' occupational stress is the outcome of structural constraints of university and personal characteristics. The results imply that the meditation of faculty members' stress can not only rely on faculty members themselves (Q3). On the one hand, professional ranking, age, and length of teaching make a difference in the level of faculty members' occupational stress. As Hans Selye stated, "The absence of stress is death". ${ }^{21}$ The faculty members should recognize the positive impact of occupational stress while striving to eliminate stressors. On the other hand, influenced by the new management trend, a considerable number of university administrators seem to have a misunderstanding, that is, that higher pressure and increasing workload can promote efficiency among the faculty members. The results of this empirical study indicate that the evaluation mechanism based on quantitative performance indicators has greatly increased the occupational pressure on the university 
faculty members. This pressure cannot increase the faculty members' academic production, and it curbs enthusiasm for research and professional identity.

\section{Conclusion}

This study was aimed at understanding the stress that university faculty members face. Since the study had limitations, the results are suggestive rather than definitive. First, since the participants were from one university, this made it difficult to generalize the results. Therefore, for future research, we will expand sample size and the sample will come from different types of universities (for example, research university, liberal art university, and technical college, etc). Second, this study relied on a scale to measure university faculty members' occupational stress; in-depth interviews with selected participants would be helpful for understanding the issues at hand. Third, we only considered five factors as possible significant predictors of faculty members' stress. There are other factors that determine the level of faculty members' stress, such as contract period and working hours. In response to increasing financial pressure and higher performance requirements, many universities have adopted contract appointment instead of tenure. The contract period usually varied from 3 to 8 years at different universities. If a faculty member wishes to renew their contract, they must meet the requirements of teaching and scientific research outlined in the contract, which also increases the pressure on the faculty members. Moreover, the overloaded scientific research and teaching work have led to university faculty members' higher mental consumption. There are no clear boundaries between their work hours and personal time. Extensive work hours can also cause job burnout and further affect the faculty members' work efficiency. Thus, we will add other factors in future research.

Despite these limitations, this study has made theoretical and practical contributions to the growing body of literature on university faculty members' occupational stress. Regarding theory, we identified five interesting factors that influence faculty members' stress, and we uncovered that the university evaluation system, which previous studies overlooked, is also an important factor in faculty members' stress. Regarding practice, university administrators should be advised to address the root of faculty members' stress because they are in the best position to reduce faculty members' stress, for example, by reducing nonacademic workload and creating a more pleasant work environment. As administrators, they should be aware of the fact that higher faculty members' stress can impair attention, memory, and judgment and lead to academic performance inefficiency. A happy teacher is a good teacher.

\section{Acknowledgments}

This article is the result of the project "Research on the power structure of university governance," supported by the National Office for Education Science Planning (No. CIA150186). The authors' very special thanks go to all the research participants.

\section{Disclosure}

The authors report no conflicts of interest in this work.

\section{References}

1. Muchinsky PM. Psychology Applied to Work. 8th ed. Belmont, CA: Wadsworth; 2007.

2. Wei B, Jiaying W. [Pressure in ivory tower: An empirical study on relationship between occupational stress and academic output of teachers in Chinese universities]. Beijing Univ Educ Rev. 2012;10(1):124-138. Chinese.

3. Wiggins K. Teaching is among the "top three most stressed occupations". Available from: http://www.tes.com/news/school-news/breaking-news/ teaching-among-top-three-most-stressed-occupations. Accessed June 25, 2018.

4. Khan EA, Aqeel M, Riaz MA. Impact of job stress on job attitudes and life satisfaction in college lecturers. Int J Inform Educ Technol. 2014;4(3):270-273.

5. Reevy GM, Deason G. Predictors of depression, stress, and anxiety among non-tenure track faculty. Front Psychol. 2014;5:701.

6. Veena G, Pushpalatha K, Mallaiah TY. Professional stress among faculty members of Mangalore University: A Study. Int J Sci Res Manag. 2016;4:4279-4286.

7. Gupta V, Rao E, Mukherjee R. Occupational stress amongst faculty members: A review of literature. Int J Res Development-A Manag Rev. 2015;4(2):18-27.

8. Mitra D, Ann M, Lisa R. A qualitative study of the UK academic role: positive features, negative aspects and associated stressors in a mainly teaching-focused university. J High Educ. 2017;41(4):566-580.

9. Jamison MR, Enrera JA. Factors affecting work productivity among the female faculty of allied medical health colleges of University of Hail, Saudi Arabia. IOSR J Nurs Health Sci. 2015;4(6):25-39.

10. Jeryl ST. Factors affecting stress among faculty members of public universities in the Philippines: A multiple regression analysis. Int $J$ Psychol Stud. 2017;9(3):64-78.

11. Brewer E, Mcmahan LJ. The relationship between job stress and job satisfaction among industrial and technical faculty educators. J Career Tech Educ. 2013;20(1):37-50.

12. Sharma E. Stressors: A Challenge for the Faculty Members of the Higher Educational Institutions. Case Stud Bus Manag. 2014;1(2):22-33.

13. Rafeeq M, Harish P. Work life balance (WLB) is life-work balance (LWB): An innovative approach on teaching faculties in private rural higher educational institutions. IOSR J Bus Manag. 2015;17(4):22-30.

14. Mika K, Kazuhiro O, Masahito T, Tetsuya T, Beth K. Occupational Stress and Its Related Factors among University Teachers in Japan. Health. 2014;6(5):299-305.

15. Donovan RA. Perceptions of stress, workload, and job satisfaction among HSS faculty: Executive summary. Available from: http://dean. hss.kennesaw.edu/docs/tea-terrace_donovan-06-12_exec-summary.pdf. Accessed September 15, 2018.

16. Hart JL, Cress CM. Are women faculty just “worrywarts?” Accounting for gender differences in self-reported stress. In David RB, Gale EM, editors. Faculty Stress. New York, NY: Routledge; 2009:174-192. 
17. Akbar A, Akhter W. Faculty stress at higher education: A study of the business schools of Pakistan. Int J Soc Behav Educ Econ Bus Indust Eng. 2011;5(1):93-97.

18. Merchant ZA, Shastri S. Exploring job satisfaction, stress, and coping: Strategies employed by engineering faculty. Int J Sci Res. 2013;2(10):72-77.

19. Archibong IA, Bassey AO, Effiom DO. Occupational Stress Sources among University Academic Staff. Eur J Educ Stud. 2010;2(3):217-225.
20. Colacion QH, Gemora RB. Causes and effects of stress among faculty members in a state university. Asia Pac $J$ Multidiscip Res. 2016;4(1):18-27.

21. Selye H. Stress without distress. 1st ed. Philadelphia: Lippincott Williams \& Wilkins; 1974.
Psychology Research and Behavior Management

\section{Publish your work in this journal}

Psychology Research and Behavior Management is an international, peerreviewed, open access journal focusing on the science of psychology and its application in behavior management to develop improved outcomes in the clinical, educational, sports and business arenas. Specific topics covered in the journal include: Neuroscience, memory and decision making; Behavio

Submit your manuscript here: https://www.dovepress.com/psychology-research-and-behavior-management-journal 